1 Campbell RWF, Gardiner P, Amos PA, Chadwick D, Jordan RS. Measurement of the QT interval. Eur Heart f 1985;6(suppl D):81-5.

2 Cowan JC, Yusoff K, Moore $M$, et al. Importance of lead selection in QT interval measurement. $A m \mathcal{F}$ Cardiol 1988;61:83-7.

3 Higham PD, Hilton CJ, Aitcheson DA, Furniss SS, Bourke JP, Campbell RWF. QT dispersion does reflect regional variation in ventricular recovery. Circulation 1992;86(suppl I):392.

4 Mirvis DM. Spatial variation of the QT intervals in normal persons and patients with acute myocardial infarction. $\mathcal{A}$ Am Coll Cardiol 1985;5:625-31.

5 Higham PD, Furniss SS, Campbell RWF. Increased OT dispersion in patients with ventricular fibrillation followin

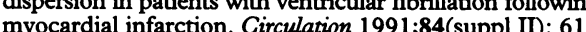
myocardial infarction. Circulation 1991;84(suppl II): 61. Heperfusion, acute myocardial infarction Reperfusion, acute myocardial infarction and
dispersion [abstr]. Eur Heart $\mathcal{f}$ 1992;13(suppl):448.
7 Day CP, McComb JM, Campbell RWF. QT dispersion an indicator of arrhythmia risk in patients with long QT intervals. Br Heart $\mathcal{F} 1990 ; 63: 342-4$.

8 Linker NJ, Colonna P, Kekwick CA, Till J, Camm AJ, Ward DE. Assessment of QT dispersion in patients with congenital long QT syndromes. Am f Cardiol 1992; 69:634-8.

9 Day CP, McComb JM, Matthews J, Campbell RWF Reduction in QT dispersion by sotalol following myocardial infarction. Eur Heart f 1991;12:423-7.

10 Hii JTY, Wyse DG, Gillis AM, Duff HJ, Solyo MA Mitchell LB. Precordial QT interval dispersion as a marker of torsades de pointes. Disparate effects of class marker of torsades de pointes. Disparate effects of class 1992;86:1376-82.

11 de Bono DP, Bhullar HK, Goddard WP. Automated measurement of QT dispersion identifies patients at risk measurement of QT dispersion identifies patients at risk
from ventricular tachycardia [abstr]. Eur Heart $\mathcal{f} 1992$; 13:369.

\title{
Commentary
}

\section{Is this the end of the aspirin and vein graft story?}

Fourteen years and at least 20 randomised studies after the issue was first raised, antiplatelet therapy after coronary artery bypass grafting remains a subject for research trials, with apparent uncertainty among clinicians about the applicability of the various trials to clinical practice. van der Meer et al investigated whether aspirin or warfarin should be used, and if aspirin at what doses, when should it be started, and for how long it should be continued. ${ }^{1}$ During grafting the endothelium of the saphenous vein is damaged by harvesting and during insertion into the arterial system. Subsequent platelet adhesion to exposed subendothelial tissue causes thrombus formation. Approximately $10 \%$ of vein grafts occlude within the first three months, and a further $10 \%$ are lost by one year, with $2 \cdot 5-5 \%$ a year being lost thereafter. The antiplatelet agents so far tested in trials are being used as antithrombotic agents because many of them were used to reduce the early failure rate, thought due to thrombotic occlusion, rather than the late (greater than one year) loss, which was thought to be caused by the development of intimal hyperplasia.

Results from the various trials may be difficult to compare because they are confounded by variables such as the timing of the start of treatment, the dose given, its mode of administration, whether grafts or anastomoses are being counted, the diameter of the grafted artery, the adequacy of its run off, and surgical consistency (early thrombotic occlusion may be influenced to some degree by technical factors including whether or not endarterectomy was undertaken). Information on which agent should be given, when it should be started, and in what dose can, however, be summarised. The choices of regimens seem to be-aspirin alone, aspirin plus dipyridamole, or warfarin. Several trials showed that aspirin in a dose of $325 \mathrm{mg}$ once a day is as good as aspirin plus dipyridamole, though when lower doses of aspirin were evaluated additional dipyridamole seemed to confer an advantage. Doses greater than $325 \mathrm{mg}$ once a day or of $325 \mathrm{mg}$ given more than daily increased gastrointestinal side effects with no added efficacy. The lack of a placebo group in the Dutch trial in which $50 \mathrm{mg}$ of aspirin was used and other ex vivo evidence of reduced efficacy of such a dose on platelet thromboxane $A_{2}$ inhibition mean that there is still no reliable evidence to indicate that any dose other than $325 \mathrm{mg}$ is appropriate.

\section{What of warfarin?}

Several trials, including that of van der Meer et al showed that aspirin is as good as warfarin. This is perhaps not surprising because aspirin, in preventing early occlusion, is being used as an antithrombotic agent. Because of its association with increased morbidity and the need for regular testing of the international normalised ratio warfarin is less and less used.

\section{When should aspirin be started?}

There has been considerable argument about the best time to start treatment. Ideally aspirin should be present when interaction between the damaged vessel wall and blood starts; this suggests that it should be given preoperatively. Indeed a meta-analysis of 13 randomised trials confirmed that greater efficacy is seen with earlier treatment. However, studies have shown that aspirin given as a single preoperative dose was no better than when it was given 6 hours after the procedure. Whereas aspirin given earlier did not seem to increase blood loss there was a non-significant but worrying increase in the reoperation rate $(4 \cdot 8 \%$ v $1 \cdot 0 \%)$. Aspirin can be given within 6 hours via a nasogastric tube or as a suppository.

\section{How long should aspirin be continued?}

In trials of its influence on graft patency aspirin was of confirmed benefit in the first year, especially by reducing thrombotic events in high risk grafts. The current view is that aspirin should be continued indefinitely, but the benefits of long-term aspirin have not been established.

Thus evidence from published trials suggests that the best available treatment to prevent thrombotic occlusion of vein grafts is aspirin given as sole agent in a dose of $325 \mathrm{mg}$ by mouth, within 6 hours of the operation and continued for at least one year. Even so, up to $7 \%$ of grafts may still occlude early, and late failure remains a problem. The challenge is to reduce the incidence of early thrombosis further while maintaining systemic haemostasis and also to promote long-term vein graft patency by inhibiting intimal hyperplasia. This process continues to occur after angioplasty despite nearly fifty trials of prevention in the past six years.

Division of Cardiology,

A H GERSHLICK

Department of Medicine,

Glenfield General Hospital,

Leicester $L E 39 Q P$.

1 van der Meer J, Hillege HL, Kootstra GJ, Ascoop CAPL, Pfisterer M, van Gilst WH, Lie KI, for the CABADAS research group of the Gilst WH, Lie KI, for the CABADAS research group of the Interuniversity Cardiology Institute of the Netherlands. Prevention of one-year vein-graft occlusion after aortocoronary bypass surgery: a comparison of low-dose aspirin, low-dose aspirin
oral anticoagulants. Lancet 1993;342:257-63. 